years, In 1987-88, for example, the APSR Book Review received 1,500 books and selected $418-28 \%$ - for review (Patterson, Ripley and Trish PS 1988, 912-13).

As Table 6 shows, the distribution of books reviewed is largely shaped by the distribution of books received in the various fields.

\section{Concluding Comments}

Whatever the difficulties and errors along the way, I hope and believe that the Review continues to publish the best of scholarship in political science. I am grateful to the Association and the Council for their support and to book review editor Melissa Collie and her team, associate editor Linda Lindenfelser, the 1992-93 APSR interns (Lynn Jarrell, Matt Gabel, Laura Stevens, and Frank Bell), copy editor Michael Lane, and the members of the $A P S R$ Editorial Board for all their strenuous efforts in making possible the accomplishments of the Review this year.

\section{References}

Patterson, Samuel C., John M. Bruce, and Martha Ellis Crone. 1991. "The Impact of the American Political Science Review." PS: Political Science \& Politics 24(4): $765-74$

Patterson, Samuel C., Brian D. Ripley, and Barbara Trish. 1988. "The American Political Science Review: A Retrospective of Last Year and the Last Eight Decades." PS: Political Science \& Politics 2!(4): 908-25.

Patterson, Samuel C. and Shannon K. Smithey. 1990. "Monitoring Scholarly Journal Publication in Political Science: The Role of the APSR." PS: Political Science \& Politics 23(4): 647-56.

Zinnes, Dina A. 1983. "Report of the Managing Editor of the American Political Science Review," PS 16(Fall): 810-13.

\section{United States Information Agency Initiates Summer Institute on the American Political System}

The United States Information

Agency awarded grants to support a "Summer Institute on the American Political System for Foreign Educa-

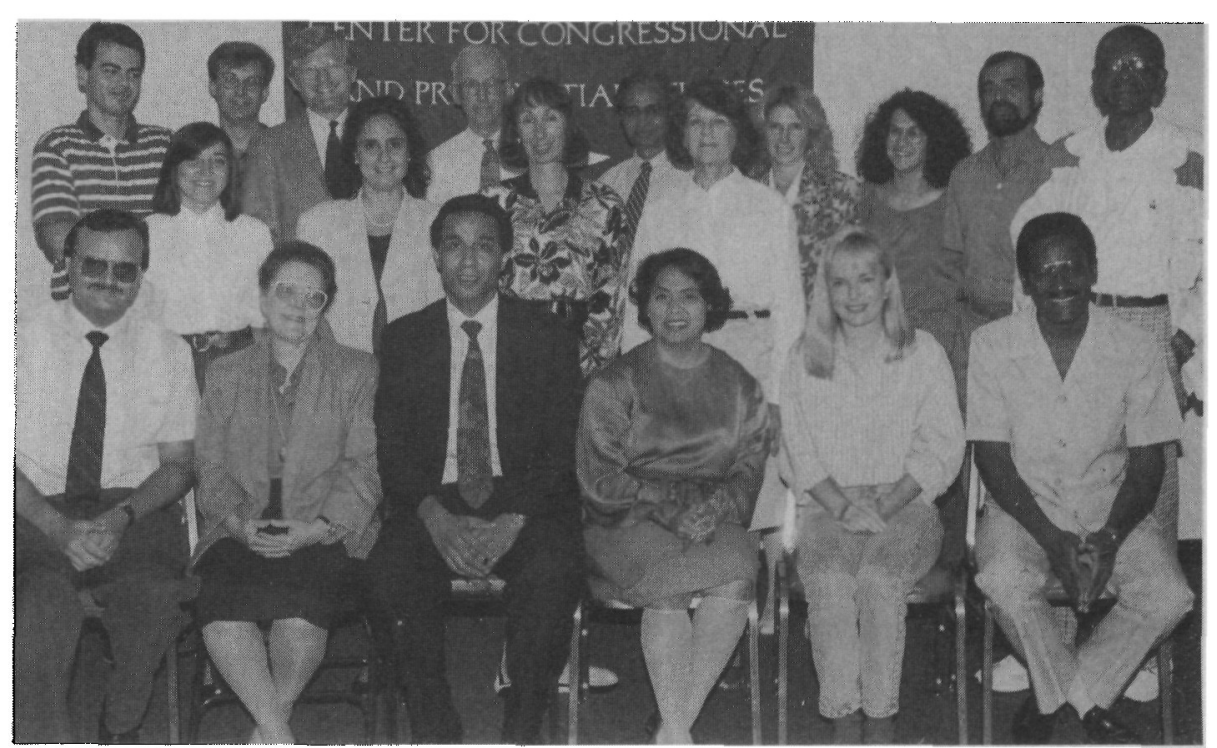

Participants and Directors, Visiting Faculty, AU-APSA Summer Institute. Front row (left to right): Laszlo Vass, Angela Moyano, Fouad Shehab, Natalie M. L. M. Morales, Maree-Anne Reid, Johannes Breeveld. Middle row: Birsen Ors, Marta Rey-Garcia, Sheilah Mann, Susan W. Hammond. Back row: Edgar Nassar-Guier, Bertjan Verbeek, James R. Thurber, Frank J. Sorauf, Golam Morshed, Candace J. Nelson, Kalliopi Spanou, Jayadeva Uyangoda, Fabien Eboussi-Boulaga.

tors" at the American University and at Southern Illinois University. The American Political Science Association was a co-sponsor of the Summer Institute hosted by The American University. The two programs offered the faculty participants from other countries an intensive study of American politics and government along with consultations with U.S. faculty on research and teaching.

The sixteen faculty attending the institute at American University were:

Johannes Breeveld, Anton de Kom University, Paramaraibo, Suriname

Fabien Eboussi-Boulaga, University of Yaounde, Yaounde, Cameroon

Takeshi Matsuda, Osaka University of Foreign 'Studies, Osaka, Japan

Natalia M. L. M. Morales, University of the Philippines, Manila, Philippines

Golam Morshed, Rajshahi University, Dhaka, Bangladesh

Angela Moyano, Instituto Tecnologico de Estudios Superiores de Monterrey, Queretaro, Mexico City, Mexico

Edgar Nassar-Guier, Autonomous University of Central America, San Jose, Costa Rica

Birsen Ors, Istanbul University, Istanbul, Turkey

Iqbal Ahmed Qureshi, University of
Sindh, Islamabad, Pakistan Maree-Anne Reid, University of Queensland, Canberra, Australia

Marta Rey-Garcia, Complutense University Madrid, Madrid, Spain

Fouad Shehab, The University of Bahrain, Manama, Bahrain

Kalliopi Spanou, Athens University, Athens, Greece

Jayadeva Uyangoda, University of Colombo, Colombo, Sri Lanka

Laszlo Vass, Budapest University of Economic Studies, Budapest, Hungary

Bertjan Verbeek, Free University of Amsterdam, The Hague, Netherlands

The AU/APSA program used its Washington, D.C., location to offer presentations not only by political scientists but also by politicians, federal officials, and journalists. Site visits were made to Congress, the National Archives, C-SPAN, the State Department, and Annapolis for a program on federalism and state government. James A. Thurber and Susan W. Hammond were the Institute's co-directors, Candace J.

Nelson, the coordinator, and Sheilah Mann, the education director.

American University faculty contributing to the program as lecturers were: Laird Anderson, Christine Degregorio, Katherine Farquhar, 


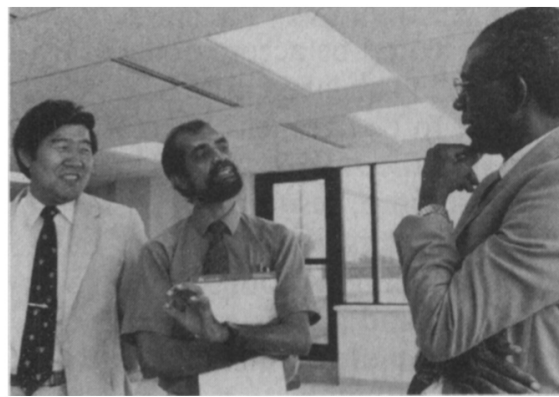

AU-APSA Summer Institute. Left to right: Takeshi Matsuda, Jayadeva Uyangoda, Fabien Eboussi-Boulaga.

Cornelius Kerwin, Laura Langbein, William Leo Grande, Herman Schwartz, and Richard Smolka. Matt Bonham, Steve Cohen, Anna Nelson, John M. Richardson, Jr., and Bernard Ross advised the participants on research projects. Philip Brenner, Greg Ivers, David Rosenbloom, and Ronald D. Shaiko served as both lecturers and consultants.

Political scientists who were guest lecturers included: Richard Baker, historian, U.S. Senate; Janet Breslin, National War College; Roger Davidson, University of Maryland; Christopher Deering, George Washington University; Christopher Foreman, Brookings; Stephen E. Frantzich, U.S. Naval Academy; Cynthia E. Harrison, Federal Judicial Center; Paul Herrnson, University of Maryland; A. E. Dick Howard, University of Virginia; Charles O. Jones, University of Wisconsin; Robert Katzmann, Brookings; John Kingdon, University of Michigan; Theodore Lowi, Cornell University; Thomas E. Mann, Brookings; James Pfiffner, George Mason University; Rep. David E. Price (D-NC); Catherine I. Riley, University of Maryland; Catherine E. Rudder, APSA; Frank Sorauf, University of Minnesota; Stephen Wayne, Georgetown University; R. Kent Weaver, Brookings; Joseph White, Brookings; Linda Williams, University of Maryland.

\section{USIA Summer Institute at Southern Illinois University at Carbondale}

The Department of Political Science and the School of Law at Southern Illinois University at Carbondale played host to 18 international educators this summer. The program was approved by the United States Information Agency (USIA)

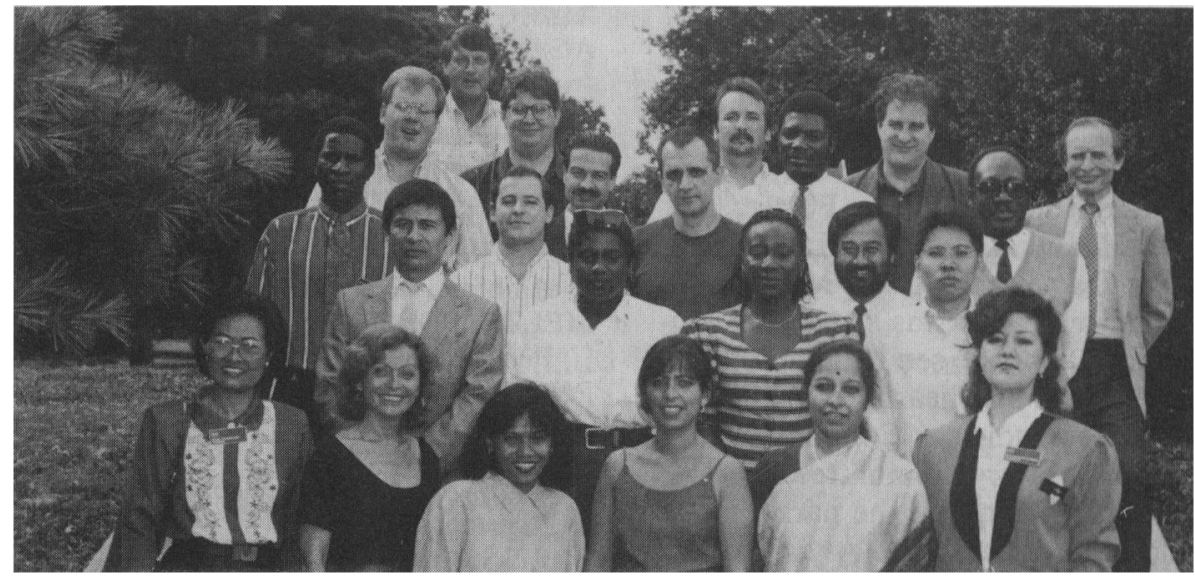

Participants in USIA Summer Institute at Southern Illinois University. Front row (left to right): Nipa Chaisavate (Thailand), Maria Eugenia Morales (Chile), Ningrum Sirait (Indonesia), Claudia Velez (Colombia), V. Yoga Jyotsna (India), Zaure Ayyupova (Kazakhstan); Second row: Alisher Baltayev (Uzbekistan), Evadne Brewster (Barbados), Sandra Pepera (Ghana), Winston Kwan Wan Ng (Hong Kong); Third row: Admore M. Kambudzi (Zimbabwe), Leonardo Hekimian (Argentina), Nenad Zakosek (Croatia), Kapil Shrestha (Nepal); Fourth row: Gordon Freer (South Africa), Mohammed Mustafa (Jordan), Kholisani Solo (Botswana), Richard Okumu Wengi (Uganda); Fifth row: Richard Kuehl (SIUC), James Leibert (SIUC), William Poole (SIUC), Michael Esler (SIUC), John S. Jackson (SIUC, Project Director).

and was entitled, "The Summer Institute in the American Political System." The participants were all faculty members in political science or law in colleges and universities in their home countries. There were 18 nations represented in the seminar, including five from Africa, three from Latin America, one from the Caribbean, one from the Middle East, one from Europe, two from Central Asian Republics with membership in the Commonwealth of Independent States, and five from Asia. Most of the participants were from nations undergoing fundamental regime or systemic transition, and several were emerging democracies.

The 18 faculty attending the institute at Southern Illinois University were:

Sandra J. Pepera, University of Ghana, Ghana

Zaure Karimovna Ayupova, Alma Ata State University, Kazakhstan

Nipa Chaisavate, Prince of Songkhia University, Thailand

Claudia Patricia Rodriquez Velez, Los Andes University-Bogota, Colombia

Evadne Arlene Brewster, Barbados Community College, Barbados

Yoga Jyotsna, Osmania University's Women's College, Hyderabad, India

Ningrum Natasyia Sirait, University of North Sumatra, Indonesia
Maria Eugenia Morales, University of Chile, Chile

Leonardo Pablo Hekimian, Catholic University of Buenos Aires, Argentina

Kholisani Solo, University of Botswana, Botswana

Admore Mupoki Kambudzi, University of Zimbabwe, Zimbabwe

Richard Okumu Wengi, Makerere University, Uganda

Kapil Shrestha, Tribhuvan University, Nepal

Winston Kwan Wan Ng, University of Hong Kong, Hong Kong

Gordon Struthers Freer, University of the Witwatersrand, South Africa

Alisher Rasulovich Baltaev, Tashkent State Law Institute, Uzbekistan

Nenad Zakosek, University of Zagreb, Croatia

Moh'd Mustafa, University of Jordan, Jordan

The seminar included five weeks in Carbondale with daily lectures on American Government and Politics and the American Legal System, with a special focus on the 1990 Clean Air Act as a case study of the policymaking and implementation process in the United States. Part of one week was spent at the state capital in Springfield and side trips were taken to St. Louis and Chicago for cultural enhancement.

Lectures were given by the follow- 
ing political science faculty at Southern Illinois University at Carbondale: John S. Jackson, Michael Esler, Barbara L. Brown, Ron Mason, David Kennedy, William Garner, William Turley, John L. Foster, John H. Baker, Manfred Landecker, David Derge, and Albert Melone.

The final week was spent in Washington, D.C. The seminar toured Capitol Hill and heard lectures on the House Judiciary Committee, the Senate Judiciary Committee, the Supreme Court, and the party caucuses in the House. A visit to the White House also included a briefing from Clinton Administration of ficials on intergovernmental relations, budgeting, and health care plans. The seminar participants also visited the Joint Center for Political and Economic Studies, the American Bar Association, the American Political Science Association, and the World Bank.

The USIA program is designed to provide these international faculty members with the latest knowledge in American politics as well as introducing state-of-the-art teaching materials. It is also designed to deepen the participants' understanding of American culture in general and the American political culture in particular. John S. Jackson, dean of the College of Liberal Arts, and Harry Haynsworth, dean of the School of Law, obtained the grant and led the seminar.

\section{Omissions from the APSA Undergraduate Directory}

The following school was omitted from the 1993-95 Directory of Undergraduate Political Science Faculty.

Christopher Newport University, Newport News, Department of Government and Public Affairs, 50 Shoe Lane, Newport News, VA 23606. Phone: (804) 594-7469. Fax: (804) 594-7713.

\section{FACULTY}

NAME: Doane, Robert D.

ACADEMIC: (Ph.D., Temple, 1973; Professor)

FIELDS: COMP (Canada), POLTHOUGHT

PHONE: 594-7091
NAME: Greenlee, Harry

ACADEMIC: (J.D., Ohio State, 1983; Assistant Professor)

FIELDS: PUBLAW (Labor Policy)

PHONE: 594-7820

NAME: Killiam, Paul C. (Chair)

ACADEMIC: (Ph.D., Massachusetts at Amherst, 1976; Professor)

FIELDS: POLICY (Environmental Policy), POLTHOUGHT

PHONE: 594-7048

NAME: Lehoucq, Fabrice E.

ACADEMIC: (Ph.D., Duke, 1992; Assistant Professor)

FIELDS: COMP (Latin America), PRES, LEG

PHONE: 594-7971

NAME: Miller, Buck G.

ACADEMIC: (Ph.D., New York University, 1980; Associate Professor)

FIELDS: PA, POLICY (Science and Technology)

PHONE: 594-7821

NAME: Nicholson, Lewis L.

ACADEMIC: (M.A., Webster, 1982; Assistant Professor)

FIELDS: POLICY (Criminal Justice), AMERICAN

PONE: 594-7097

NAME: Wall, David L.

ACADEMIC: (Ph.D., Iowa, 1990; Assistant Professor)

FIELDS: POLICY (Environmental Policy), ECONOMY (Central America)

PHONE: 594-7972

NAME: Williams, C. Harvey Jr.

ACADEMIC: (M.A., Virginia, 1962; Associate Professor)

FIELDS: AMERICAN, POLICY

PHONE: 594-7264

NAME: Winter, William C.

ACADEMIC: (Ph.D., American, 1976; Professor)

FIELDS: URBAN, METHODS, PA

PHONE: 594-7092

\section{From the Executive Director}

Dear APSA Members:

Our printer, the William Byrd

Press, Inc., has reported the first year figures on the changes in the APSR.

As you remember, we enlarged the page size in order to reduce costs (especially to abate increasing future costs) and to increase the amount of text that could be accommodated by each issue. The larger trim size was not only to be cheaper but to allow us to ship the $A P S R$ and $P S$ together in shrink wrap, resulting in postage savings and less damage to the journals in shipping. Another benefit was that tables and graphs could be presented in a more readable manner in the larger format.

Our expectations have been met. The $A P S R$ now prints the equivalent of 72 pages more per issue or 288 more per volume of the current size of the $A P S R$, and 340 more pages or a full extra issue of the $A P S R$ in its former size. In dollar terms, this addition, conservatively estimated, is worth $\$ 15,557$ to the Association. Even with the extra pages, we spent $\$ 2,392$ less on printing this year than we would have under the old format. The plastic wrap and combined mailing save APSA another $\$ 12,800$ per year.

In short, we have completely halted the seemingly inexorable forward march in our printing costs and have increased space in the journal at the same time. Not least, the journals arrive at doorsteps intact. For the additional authors whose books now get reviewed or for the political scientist whose article is published, the non-monetary value of the increased space is considerable.

Managing Editor Bing Powell has taken excellent advantage of the new possibilities of presenting tables and graphs in a readable fashion under the new format. He and PS Editor Rob Hauck have both been extraordinarily flexible in arranging their production schedules so that the two journals could be printed together.

Change is always difficult. We owe a special debt of gratitude to everyone who has worked to make this transition successful, in particular Bing Powell, Sheilah Mann, and Rob Hauck, and to everyone who preferred the old trim size but who tolerated the change.

Sincerely, Catherine Rudder 